\title{
Uncoupling of the Noradrenergic- Hypothalamic-Pituitary-Adrenal Axis in Panic Disorder Patients
}

Jeremy D. Coplan, M.D., Daniel Pine, M.D., Laszlo Papp, M.D., Jose Martinez, M.A., Thomas Cooper, M.A., Leonard A. Rosenblum, Ph.D., and Jack M. Gorman, M.D.

In this paper the authors examine the interrelationship of both the noradrenergic (NA) system and the hypothalamic-pituitary-adrenal (HPA) axis and its implications for panic disorder (PD). Seventeen $P D$ patients and 16 healthy volunteers were challenged orally 12 weeks apart with the $\alpha_{2}$-agonist clonidine (13 healthy volunteers and 12 patients repeated the challenge). Between challenges, PD patients were treated with fluoxetine, with 10 of 12 improving at least moderately. Both during the acute phase of the illness and during the phase of pharmacological improvement, patients demonstrated a greater percentage of reductions of plasma 3-methoxy-4-hydroxyphenylglycol (MHPG) and plasma cortisol during clonidine challenge. We used correlational matrices to examine the relationship between the NA system, as reflected by plasma MHPG, and the HPA axis, as reflected by plasma cortisol measures. Healthy volunteers exhibited multiple significant "couplings" between either baseline or maximal decrease $\left(\Delta_{\max }\right)$ of plasma MHPG, with either baseline or $\Delta_{\max }$ plasma cortisol measures both within the first and second challenges and between the first and second challenges. In contrast, PD patients demonstrated "uncoupling" of the NA system and the HPA axis, with no significant correlations observed between either baseline and/or maximal decrease $\left(\Delta_{\max }\right)$ measures of MHPG with the same cortisol measures for either the first or second challenge. The same uncoupling was observed for NA/HPA correlations between the first and second challenges. These data suggest that the hyperresponsivity to clonidine in PD patients persists during fluoxetine treatment. They also raise the possibility that an uncoupling of the NA system and the HPA axis may be a feature of $P D$ patients, even following clinically significant improvement. The authors suggest suboptimal NA regulation of the HPA axis in PD patients, with pathophysiological implications particularly prominent during periods of stress-induced activation of the two systems. [Neuropsychopharmacology 13:65-73, 1995]
KEY WORDS: Panic disorder; Fluoxetine; Clonidine; Noradrenergic system; Hypothalamic; Pituitary; Adrenal axis

From the College of Physicians and Surgeons of Columbia University, (JDC, DP, LP, JM, TC, JMG), Department of Psychiatry (LAR), State University of New York-Health Science Center at Brooklyn, New York, and the Phobia and Stress Clinic, Hillside Hospital (JDC, LP, JMG), Long Island Jewish Medical Center, New York, New York. Address correspondence to: Jeremy D. Coplan, M.D., 722 West 168th Street, Box 24, New York, New York 10032.

Received October 10, 1994; revised December 23, 1994; accepted January 9, 1995.
Noradrenergic (NA) overactivity, primarily reflected by challenge studies using the $\alpha_{2}$-agonist clonidine and $\alpha_{2}$-antagonist yohimbine, has been implicated in the pathophysiology of panic attacks (Charney et al. 1984; Cameron et al. 1990; Uhde et al. 1992). Hypothalamicpituitary-adrenal (HPA) axis overactivity has been more extensively investigated in the pathophysiology of mood disorders, whereas its dysfunction in panic disorder has been viewed as more phasic and subtle (for review, see Klein 1993).

Activation of the HPA axis by norepinephrine is complex and involves excitatory ( $\alpha_{2}$ adrenoceptors) 
and inhibitory components ( $\alpha_{1}-\beta$ adrenoceptor function) which influence corticotropin-releasing-factor (CRF) secreting neurons of the paraventricular nucleus of the hypothalamus. Direct excitatory sympathetic effects of adrenal function are also relevant (Chrousos and Gold 1992; Charney et al. 1993). Moreover, CRF, the key regulating neuropeptide of the HPA axis, provides a significant excitatory influence on noradrenergic neurons located in the locus ceruleus; (Butler et al. 1990). The overall effect of locus ceruleus activation is to increase CRF release (Chrousos and Gold 1992; Charney et al. 1993). The two interacting systems have been viewed as participating in a mutually reinforcing feedback loop that is particularly active under stressful conditions (Charney et al. 1993).

In this report we examine the relationship between the NA system, as reflected by baseline plasma 3-methoxy-4-hydroxyphenylglycol (MHPG) levels and the maximal decrease $\left(\Delta_{\max }\right)$ of plasma MHPG to clonidine, and the HPA axis, as indicated by baseline plasma cortisol levels and the $\Delta_{\max }$ of plasma cortisol during clonidine challenge, in patients with panic disorder and in healthy volunteers. Patients were studied, using repeated clonidine challenges, both in the acute state and while in a state of fluoxetine-induced improvement. Healthy volunteers also underwent repeat clonidine challenges but without any intervening treatment.

\section{METHODS}

\section{Subjects}

Seventeen patients meeting DSM-III-R criteria for panic disorder (PD) with or without agoraphobia as assessed by a structured clinical interview (Spitzer et al. 1990) were recruited through advertisements in local newspapers. Patients were informed that they would receive two oral clonidine challenges separated by twelve weeks of fluoxetine treatment. Patients with concurrent depressive symptoms were not excluded if the depression was deemed secondary to the panic disorder and they did not meet DSM-III-R criteria for current major depression. Patients with a lifetime history of bipolar disorder, schizophrenia, obsessive-compulsive disorder, and substance and/or alcohol abuse within the previous six months were excluded. Sixteen healthy subjects, as assessed by the Schedule for Affective Disorders and Schizophrenia (Endicott and Spitzer 1978), served as a control group. Healthy volunteers were excluded if first-degree relatives were affected by a major psychiatric disorder, but Axis II pathology was not an excluding criterion (American Psychiatric Association 1987).

The subjects' routine baseline evaluation included a physical examination, blood tests for liver profile and electrolyte function, complete blood count and thyroid function tests, electrocardiogram, pregnancy test, and urinalysis. Patients were medication free for four weeks before the study began, except benzodiazepines as needed. Five patients took benzodiazepines as needed up to three days prior to the first clonidine challenge, and two of these took benzodiazepines as needed up to three days prior to the second challenge. Before the first challenge, PD patients were evaluated using the Hamilton Depression Scale, Hamilton Anxiety Scale, and Clinical Global Severity Scale (see Schneier et al. 1990); the number of panic attacks experienced by subjects during the week prior to the evaluation was tallied. None of the patients were assessed to be experiencing benzodiazepine withdrawal during the clonidine challenges. Women were studied during the first half of their menstrual cycle. Thirteen of $17 \mathrm{PD}$ patients and 12 of 16 volunteers repeated the clonidine challenge.

\section{Sample Characteristics}

There was no significant difference in sex distribution between the groups (patients $=7$ males and 10 females; controls $=8$ males and 8 females; Pearsonian $\chi^{2}=.26$, $d f=1, \mathrm{NS})$. The patients $(n=17)$ tended to be older than the control subjects ( $n=16$; mean in years was $40.53 \pm 10.24$ versus $33.94 \pm 10.45$ years; $t=1.83 ; d f=$ $31, p=.077$ ) (two-tailed). There was no weight difference between groups.

\section{Challenge Procedures}

At 9:00 A.M., an indwelling venous cannula was placed into an antecubital vein of each subject and kept open with heparinized solution. Subjects remained in a semireclining comfortable position. at 9:30 A.M. (0 time), clonidine $(0.15 \mathrm{mg})$ ws given by mouth. Blood samples were drawn at time $=0,60,120,180$, and 240 minutes for plasma MHPG and plasma cortisol levels. Clonidine blood levels were measured at 60,120 , and 180 minutes. Human growth hormone levels drawn during the same procedure are reported in a separate document (Coplan et al. in press).

\section{Treatment Phase}

Following completion of the challenge study, patients were entered into an open, flexible, treatment phase. Patients were started at $2.5 \mathrm{mg} /$ day of fluoxetine, which was increased by $2.5 \mathrm{mg} /$ day every 5 days to a minimum of $20 \mathrm{mg} /$ day or until the patient was unable to tolerate further dosage increases. No minimum dose was stipulated. Every two weeks the dose could be raised by $20 \mathrm{mg} /$ day up to a maximum of $60 \mathrm{mg} /$ day, if clinical response was judged insufficient. Titration of the final fluoxetine dose used the method outlined by 
Schneier et al. (1990). The mean final dose of fluoxetine was $17.7 \pm 16.7 \mathrm{mg} /$ day.

\section{Biochemical Analyses}

Clonidine blood levels were quantitated via gas chromatography mass-spectrometry in the simultaneous ion-monitoring mode using methodology developed in this laboratory (Thomas Cooper, unpublished data). Within-run and between-run relative standard deviation were $4.2 \%$ and $5.6 \%$, respectively. The lower limit of detection is $100 \mathrm{pg} / \mathrm{ml}$.

Plasma MHPG was measured by gas chromatography mass-spectrometry operated in the simultaneous ion-monitoring mode using deuterated MHPG as an internal standard. The method is essentially the same as that of Jimerson et al. (1981).

Plasma cortisol determinations were conducted using a competitive protein-binding modification of the method descried by Murphy (1967).

\section{DATA ANALYSIS}

\section{Clonidine Levels}

In order to exclude the potential confound that may arise if significant between-group or between-challenge differences in blood clonidine levels were observed, an analysis of variance with repeated measures (ANOVAR) for group (patients versus controls), visit (first versus second clonidine challenge), and interactive effects was performed. Greenhouse-Geiger correction was used if significant autocorrelations were observed.

\section{MHPG and Cortisol Data}

Prechallenge measures (time $=0$ minutes) were analyzed using an ANOVAR for group and visit, and group-by-visit effects. To analyze challenge effects, ANOVAR was applied to the maximal $\left(\Delta_{\max }\right)$ response during the clonidine procedure. This response was calculated by taking the value at the trough response point to clonidine and subtracting the subject's baseline value, yielding in most instances a negative value. If baseline differences were observed, maximal percentage decrease of the measure was employed by using the trough point as the numerator, the baseline value as the denominator, and multiplying by 100 . tailed.

The significance level was accepted at $p \leqslant .05$, two

\section{Correlational Analyses}

The intraclass correlation coefficient (Shrout and Fleiss 1979) was used to analyze the stability of preclonidine or baseline as well as $\Delta_{\max }$ measures of plasma MHPG and plasma cortisol measures obtained during clonidine challenge. Exploratory analyses were conducted separately to examine the relationship in controls and patients between plasma cortisol and plasma MHPG baseline and $\Delta_{\max }$ measures. Only subjects who completed both challenges were analyzed. Because only two patients showed less than moderate improvement, associations between biochemical measures and clinical response could not be examined. Analyses were performed using the Pearson correlation; two-tailed $p$-values of .05 are considered significant without correction for multiple comparisons because of the exploratory nature of the study.

\section{RESULTS}

\section{Treatment Response Profile}

Patients showed robust reductions (all <.01) (see Table 1) on the Hamilton Anxiety Scale, the Hamilton Depression Scale, and the Global Severity Scale, and in the number of full-blown attacks (consisting of four or more DSM-III-R panic symptoms) when the weekly assessments performed prior to the first and second challenge days were compared. Ten of 12 patients showed at least moderate improvement; the two nonresponder patients were distinguished by using benzodiazepines as needed up to three days prior to the second challenge.

The panic attack mean frequency per week was reduced following fluoxetine treatment from a mean of almost six panic attacks per week per patient to less than one panic attack per week. The mean clinical Global

Table 1. Treatment Response to Open Fluoxetine in 13 Patients with Panic Disorder

\begin{tabular}{lcccc}
\hline & $\begin{array}{c}\text { Hamilton } \\
\text { Anxiety Scale }\end{array}$ & $\begin{array}{c}\text { Hamilton } \\
\text { Depression Scale }\end{array}$ & $\begin{array}{c}\text { Global } \\
\text { Severity Scale }\end{array}$ & Number of Panics \\
\hline Visit 1 & $21.6 \pm 6.39$ & $17.46 \pm 7.26$ & $4.92 \pm .86$ & $5.92 \pm 5.48$ \\
Visit 2 & $11.23 \pm 5.93$ & $9.62 \pm 8.4$ & $3.3 \pm 1.38$ & $.59 \pm 1.66$ \\
$t$-Value & 4.86 & 3.80 & 5.20 & 3.46 \\
$d f$ & 12 & 12 & 12 & 12 \\
$p$ & $<.01$ & $<.01$ & $<.01$ & $<.01$ \\
\hline
\end{tabular}

Global Severity Scale: 6 , severely ill; 5 , markedly ill; 4 , moderately ill; 3 , minimally ill; 2 , borderline ill; 1 , not ill. $p$-Value is two-tailed. Entries for Visits 1 and 2 are $\pm S D$. 
Table 2. ANOVAR Analysis of Prechallenge Biochemical Variables

\begin{tabular}{|c|c|c|c|c|c|c|c|c|c|}
\hline & $\begin{array}{c}\text { Patient } \\
n \\
\end{array}$ & $\begin{array}{c}\text { Control } \\
n\end{array}$ & $\begin{array}{l}\text { Patient } \\
\text { Visit } 1 \\
\end{array}$ & $\begin{array}{l}\text { Control } \\
\text { Visit } 1 \\
\end{array}$ & $\begin{array}{l}\text { Patient } \\
\text { Visit } 2 \\
\end{array}$ & $\begin{array}{c}\text { Control } \\
\text { Visit } 2 \\
\end{array}$ & $\begin{array}{c}\text { Group } \\
(F, d f, p)\end{array}$ & $\begin{array}{c}\text { Visit } \\
(F, d f, p) \\
\end{array}$ & $\begin{array}{l}\text { Inter- } \\
\text { action } \\
\end{array}$ \\
\hline $\begin{array}{l}\text { MHPG } \\
\quad(\mathrm{ng} / \mathrm{ml})\end{array}$ & 12 & 13 & $6.0 \pm 2.9^{a, c}$ & $4.4 \pm 1.0^{b, c}$ & $4.6 \pm 1.6^{a, d}$ & $3.7 \pm 1.0^{b, d}$ & $\begin{array}{l}4.16 \\
1,23 \\
=.05\end{array}$ & $\begin{array}{c}12.22 \\
1,23 \\
<.01\end{array}$ & NS \\
\hline $\begin{array}{l}\text { Cortisol } \\
\qquad(\mu \mathrm{g} / \mathrm{dl})\end{array}$ & 12 & 13 & $14.0 \pm 5.4$ & $11.0 \pm 5.6$ & $14.4 \pm 4.0^{e}$ & $11.1 \pm 3.9^{e}$ & $\begin{array}{l}3.29 \\
1,24 \\
=.08\end{array}$ & NS & NS \\
\hline
\end{tabular}

Challenge is $\mathbf{1 5} \mathrm{mg}$ of clonidine.

\pm Standard deviation.

${ }^{a} t=2.48, d f=11, p<.05$

${ }^{b} t=2.87, d f=12, p<.025$

${ }^{c} t=2.12, d f=23, p<.05$.

${ }^{d} t=1.79, d f=23, p=.08$.

${ }^{e} t=2.15, d f=24, p<.05$.

Severity score of the patient group was reduced from a rating of almost markedly ill to between minimally to moderately ill following treatment, suggesting a general improvement rather than complete remission of clinical symptomatology for the sample as a whole.

\section{Blood Clonidine Levels}

No group, visit, or group-by-visit interactive effects were noted with variance in subjects' plasma clonidine levels. Only a time effect was observed $(F=14.8, d f=$ $1.99 ; 92, p<.000$ [Greenhouse-Geisser corrected]), reflecting the overall increase and subsequent leveling in subjects' clonidine blood levels during the challenge procedure.

\section{MHPG Results}

The prechallenge ANOVAR analysis comparing baseline values measured on the first and second challenge day showed a group effect for plasma MHPG, indicating higher levels in patients versus controls irrespective of challenge day (see Table 2). Post hoc $t$-tests indicated that for the first visit, baseline plasma MHPG was significantly elevated in patients versus controls, and marginally elevated for the second visit. A strong visit effect was observed with significant overall reductions in preclonidine MHPG; this effect was observed in both groups from the furst to second challenge day. No group by visit interaction was observed, suggesting parallel decreases of baseline plasma MHPG from the first to second visit in both groups.

Because of the confounding effect of betweengroup baseline differences on challenge effects, we ran an ANOVAR comparing the percentage of decrease of plasma MHPG during clonidine challenge relative to baseline levels in patients versus controls. Because we were interested in the biological correlates of effective fluoxetine treatment, the two nonresponders are excluded from this analysis.

Patients showed a greater percentage of MHPG decreases when compared with the controls $(F=6.76$, $d f=1 ; 21, p=.017$ ) (see Figure 1 ). No visit or group-byvisit effect was observed following treatment. Post hoc $t$-tests comparing the maximal percentage of decrease of plasma MHPG in response to clonidine showed a significant patient/control difference for the first clonidine challenge and a nonsignificant $(p<.17)$ difference for the second clonidine challenge (see Figure 1). The absence of a group-by-visit effect suggests that despite a significant reduction in clinical symptomatology, the effects of effective fluoxetine treatment on the percentage of MHPG decreases by clonidine were not significant.

\section{Cortisol Results}

In the preclonidine ANOVAR analysis (see Table 2), patients demonstrated marginally higher prechallenge cortisol compared to the control group. Post hoc testing indicated that patients exhibited significantly higher prechallenge cortisol levels than did controls at the second visit.

Because overall baseline cortisol levels were marginally higher in the patients in comparison with the levels in controls, the maximal percentage decrease during clonidine challenge was computed. ANOVAR analysis indicated a group effect, with greater decreases in patients versus controls observed when controlling for baseline differences, but no visit or group-by-visit effects emerged. Post hoc t-tests indicated significant patient/control differences for the first and second clonidine challenge (see Figure 2). The absence of a visit effect and group-by-visit effect suggests that despite fluoxetine-induced improvement of $P D$ patients, exaggerated cortisol decreases during clonidine challenge persisted. 


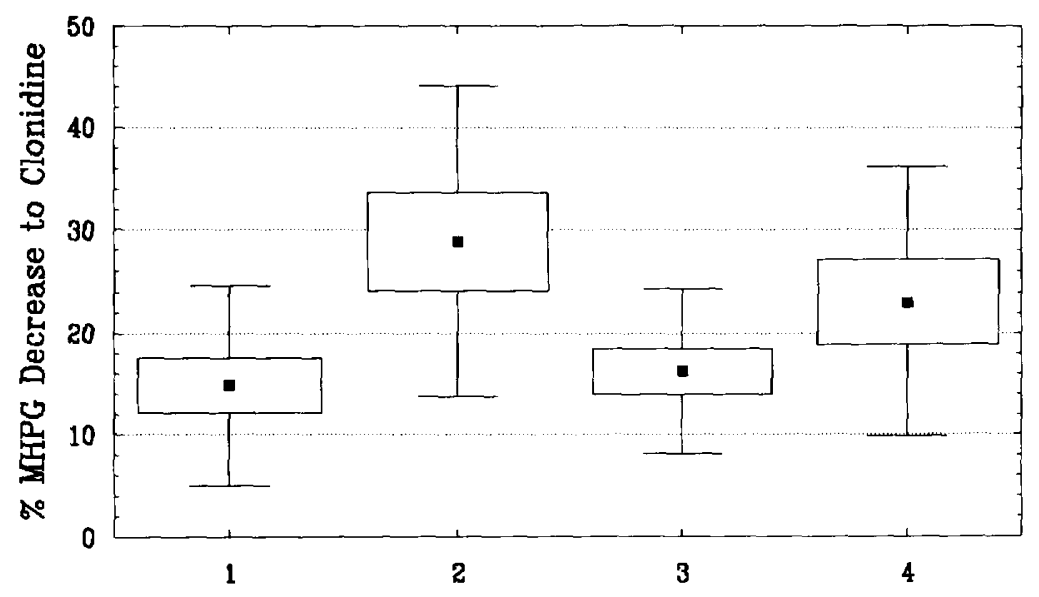

Figure 1. The percentage of MHPG decrease in relation to clonidine in patients and controls (peak decrease/baseline $* 100) . F(1 ; 21)=6.76$; $p<.02$. There were no visit or group-by-visit effects. $n=13$ healthy volunteers, 10 PD fluoxetine responders. 1 , control visit $1 ; 2$, PD pretreatment; 3 , control visit $2 ; 4$, PD posttreatment. $1<2 ; p<.02 ; 3<4$ (trend); $p<.16$. $\mathbf{\square}=$ mean, $\square= \pm \mathrm{SE}, \mathrm{I}= \pm \mathrm{SD}$.

\section{Stability of Preclonidine Biochemical Measures}

Using the intraclass correlation coefficient (Shrout and Fleiss, 1979) for preclonidine baseline measures (Table 3), plasma MHPG and cortisol appeared stable between challenges in patients and controls. For the $\Delta_{\max }$ measures obtained during clonidine challenge (Table 3), cortisol but not MHPG measures appeared stable in patients, whereas MHPG as well as cortisol measures appeared stable in controls.

\section{Relationship between Baseline and Change Measures}

Overall, high baseline levels of MHPG and/or cortisol were associated with greater declines during the clonidine challenge. During both challenges in patients, significant inverse associations occurred between baseline cortisol and its $\Delta_{\max }$ as well as between baseline MHPG and its $\Delta_{\max }$ (Table 4). For controls during the furst challenge, there were similar strong inverse associations between baseline and change measures for both MHPG and cortisol. During the controls' second challenge, the relation between baseline and change measures for cortisol remained strong, but the relation be- came much weaker for MHPG. Thus, a significant inverse relationship between baseline and $\Delta_{\text {max }}$ measures was observed in all instances, except for the controls' second challenge MHPG data.

\section{MHPG/Cortisol Correlations}

For each challenge, 4 correlations were performed in the two groups: baseline cortisol to baseline MHPG, $\Delta_{\max }$ cortisol to $\Delta_{\max }$ MHPG, baseline cortisol to $\Delta_{\max }$ MHPG, and finally $\Delta_{\max }$ cortisol to baseline MHPG. This generated 16 correlations. An additional 8 correlations were generated by correlating cortisol measures from the first challenge to MHPG measures of the second challenge and a further 8 by correlating MHPG measures from the first challenge to cortisol measures of the second challenge for a total of 32 correlations, or 16 from each group.

\section{Within-Challenge MHPG/Cortisol Correlations}

For the first challenge in the healthy volunteers, all four correlations examined were significant (Table 5); base-

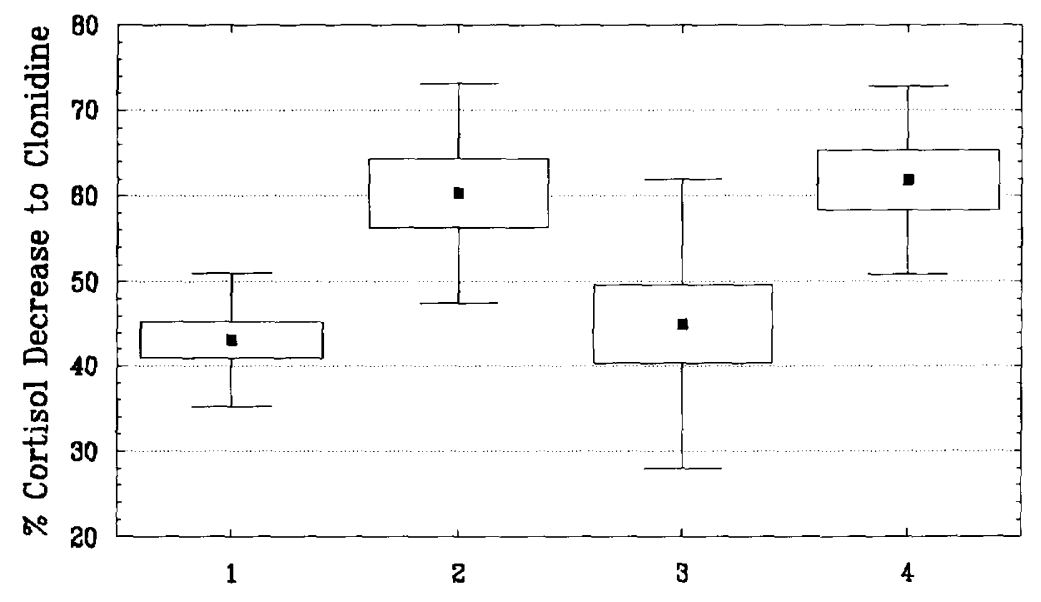

Figure 2. The percentage of cortisol decrease in relation to clonidine in patients and controls (peak decrease/baseline $* 100) . F(1 ; 21)=14.2$; $p=.001$. There were no visit or group-by-visit effects. $n=13$ healthy volunteers, 10 PD fluoxetine responders. 1 , control visit $1 ; 2, \mathrm{PD}$ pretreatment; 3 , control visit $2 ; 4$, PD posttreatment. $1<2 ; p<.001 ; 3<4 ; p<.02$. $=$ mean, $\square= \pm S E, I= \pm S D$. 
Table 3. Stability of Biochemical Measures during Repeat Clonidine Challenge

\begin{tabular}{lcc}
\hline & Patients & Controls \\
\hline Baseline MHPG & .50 & .57 \\
Change in MHPG & .17 & .66 \\
Baseline cortisol & .84 & .61 \\
Change in cortisol & .76 & .75 \\
\hline
\end{tabular}

Intraclass correlation coefficient, fixed effects model. Baseline: value prior to clonidine challenge. Change: trough minus baseline value.

line cortisol correlated significantly with baseline MHPG and $\Delta_{\max }$ MHPG. The $\Delta_{\max }$ cortisol also correlated with baseline MHPG and $\Delta_{\max }$ MHPG. The baseline to $\Delta_{\max }$ correlations were inversely significant, suggesting that high baseline levels of plasma MHPG predicted greater $\Delta_{\max }$ of plasma cortisol and vice versa.

In striking contrast, none of these between-system correlations were closely significant in the patients with $\mathrm{PD}$. Fisher's $\mathrm{r}$ to $\mathrm{Z}$ revealed that the $\Delta_{\max }$ cortisol to $\Delta_{\max }$ MHPG correlation was marginally stronger in the controls versus patients. Thus, for the first challenge, acutely symptomatic PD patients showed evidence of an absence of coupling between the NA system and the HPA axis. In contrast, healthy volunteers showed consistently significant correlations.

For the second clonidine challenge, of the four correlations tested in the controls, two were significant and one was at a trend level (Table 5). The baseline cortisol to $\Delta_{\max }$ MHPG inverse correlation was significant as well as being significantly stronger in the controls versus patients. A trend was noted for the baseline cor-
Table 4. Relationship between Baseline and Change $\left(\Delta_{\max }\right)$ Measure to Clonidine

\begin{tabular}{|c|c|c|}
\hline & Patients & Controls \\
\hline First MHPG challenge & $-.90^{* * *}$ & $-.79^{\star \star \star}$ \\
\hline Second MHPG challenge & $-.81^{* * *}$ & -.37 \\
\hline First cortisol challenge & $-.93^{* * *}$ & $-.91^{* * *}$ \\
\hline Second cortisol challenge & $-.91^{* * *}$ & $-.84^{\star \star \star}$ \\
\hline
\end{tabular}

A correlation between initial measure and change $\left(\Delta_{\max }\right)$ measure during challenge exists for both patients and controls.

$$
\begin{aligned}
& { }^{\star} p<.05 . \\
& { }^{\star *} p<.01 .
\end{aligned}
$$

tisol to baseline MHPG correlation, and a significantly positive $\Delta_{\max }$ cortisol to $\Delta_{\max }$ MHPG correlation was also observed. The latter two correlations tended to be stronger in the controls versus patients. Thus, when significantly improved by fluoxetine, patients failed to demonstrate the expected coupling process between the NA systems and the HPA axis, which was observed in the normals' second challenge.

\section{Between-Challenge MHPG/Cortisol Correlations}

The next correlational analysis explored the relationship between cortisol measures taken during the furst clonidine challenge versus MHPG measures taken during the second clonidine challenge (see Table 5). Only $\Delta_{\max }$ cortisol during the first challenge correlated significantly with $\Delta_{\max }$ MHPG during the second challenge. None of this category of correlations differed be-

\begin{tabular}{|c|c|c|c|c|}
\hline & $\begin{array}{c}\text { Baseline Cortisol } \alpha \\
\text { Baseline MHPG }\end{array}$ & $\begin{array}{c}\Delta \text { Cortisol } \alpha \\
\Delta \text { MHPG }\end{array}$ & $\begin{array}{c}\text { Baseline Cortisol } \alpha \\
\Delta \mathrm{MHPG}\end{array}$ & $\begin{array}{c}\Delta \text { Cortisol } \alpha \\
\text { Baseline MHPG }\end{array}$ \\
\hline \multicolumn{5}{|c|}{ Relationship between NA system and HPA axis during furst clonidine challenge } \\
\hline Normals $(n=13)$ & $.60^{*}$ & $.69 * *$ & $-.59 * *$ & $-.54^{\star}$ \\
\hline PD patients $(n=12)$ & -.01 & .04 & -.06 & .04 \\
\hline Fisher $\mathrm{r}$ to $\mathrm{Z} \chi^{2}$ & 2.34 & $3.09(t)$ & 1.81 & 1.97 \\
\hline \multicolumn{5}{|c|}{ Relationship between NA system and HPS axis during second clonidine challenge } \\
\hline Normals $(n=13)$ & $.46(t)$ & $.52^{*}$ & $-.58^{*}$ & -.35 \\
\hline PD patients $(n=12)$ & -.26 & -.26 & .26 & .17 \\
\hline Fisher $r$ to $Z \chi^{2}$ & $2.76(t)$ & $3.36(t)$ & $4.08^{*}$ & 1.37 \\
\hline \multicolumn{5}{|c|}{ Relationship between HPA axis during furst clonidine challenge and NA system during second challenge } \\
\hline Normals $(n=13)$ & .21 & $.53^{*}$ & -.43 & -.24 \\
\hline PD patients $(n=12)$ & -.10 & -.11 & -.01 & .25 \\
\hline Fisher $r$ to $Z \chi^{2}$ & .47 & 2.32 & 1.05 & 1.19 \\
\hline \multicolumn{5}{|c|}{ Relationship between NA system during first challenge and HPA axis during second clonidine challenge } \\
\hline Normals $(n=13)$ & $.86^{\star \star \star}$ & $.79^{\star \star \star}$ & $-.77^{* \star \star}$ & $-.86^{\star \star \star}$ \\
\hline PD patients $(n=12)$ & -.09 & .05 & .08 & .23 \\
\hline Fisher's $r$ to $Z \chi^{2}$ & $9.07^{* *}$ & $4.94^{\star}$ & $5.74^{*}$ & $11.05^{\star \star \star}$ \\
\hline
\end{tabular}
tween the groups.

Table 5. Within-Challenge and Between-Challenge MHPG/Cortisol Correlations

$t<1,{ }^{*}<.05,{ }^{* \star}<.01,{ }^{\star \star \star}<.001$. 
lenge. None of this category of correlations differed between the groups.

We then explored the relationship between NA measures taken during the first clonidine challenge to cortisol measures taken during the second clonidine challenge. All four possible correlations were at least at the $p<.001$ level in the normal controls, whereas none were significant in the patients. Moreover, all four correlations were significantly stronger in normals versus patients. Thus, MHPG measures taken during the first clonidine challenge were strongly correlated with cortisol measures taken during the second clonidine challenge only in the normals.

In summary, in the controls, 12 of 16 tested correlations were significant (one trend is included), whereas in the patients with PD, none of the same 16 correlations were significant. These data indicate a stable coupling process in the controls - over a 12-week periodwhereas the patients showed no evidence of NA/HPA coupling over the same time frame.

\section{CONCLUSIONS}

Several findings emerge from the study. PD patients demonstrated enhanced sensitivity to oral clonidine in comparison with controls, as reflected by decreases in the percentage of MHPG and cortisol in subjects during clonidine challenge both in the acute and pharmacologically improved state. This study suggests that fluoxetine-induced clinical improvement is not accompanied by alterations in $\alpha_{2}$-adrenergic function to the extent reflected by the percentage of MHPG and cortisol decreases in subjects during clonidine challenge. These statements should be qualified with the caveat that the decline of cortisol represents the combination of diurnal decline and the effects of clonidine. Without placebo-controlled comparisons, the clonidine contribution remains undetermined. A second caveat is that although an overall group effect for the percentage of MHPG decrease to clonidine was observed, the difference between the percentage of MHPG decrease in PD patients versus healthy controls for the second clonidine challenge was only at a weak-trend level $(p=.16)$.

The finding of an enhanced percentage of MHPG decreases to clonidine is consistent with some but not all studies (for review, Abelson et al. 1992). Enhanced cortisol decreases to clonidine were not observed by Stein and Uhde (1988), but were observed by Brambilla et al. (1994). The latter two studies used control saline infusions to evaluate the subjects' cortisol response to clonidine. In neither study was the natural diurnal decline of cortisol different between patients with PD and healthy volunteers. Thus, differences of cortisol response to clonidine between PD patients and controls in the current study are unlikely due to between-group differences in diurnal cortisol variation. The differences between study findings described previously may relate to differences in sample characteristics or to group differences in challenge baseline levels (Nutt 1989) or route of administration. (To our knowledge, this is the first oral clonidine study performed in adult PD patient samples.)

The second observation is that NA and HPA axis function, in contrast to the strong coupling observed in healthy volunteers, appears "uncoupled" in PD patients. Uncoupling may derive along similar lines to the blunted human growth hormone response to clonidine observed in PD patients (Uhde et al. 1992). In one model, chronic noradrenergic overdrive is believed to desensitize postsynaptic $\alpha_{2}$-adrenergic receptors of hypothalamic neurons which modulate the release of growth-hormone releasing hormone. Chronic and/or episodic overactivity of central NA projections may also lead to a generalized but possibly differential downmodulation of postsynaptic hypothalamic adrenoceptor subtypes that exert a stimulatory or inhibitory influence over CRF-releasing neurons of the paraventricular nucleus. In addition, alteration of the sensitivity of presynaptic $\boldsymbol{\alpha}_{2}$-adrenergic receptors may also affect the activity of NA projections to the paraventricular nucleus of the hypothalamus. A positive correlation between MHPG change and cortisol change to clonidine in the healthy volunteers suggests that, under normal circumstances, reduction of cortisol secretion occurs parallel to reduction of NA turnover. Conversely, in acutely ill PD patients, the exaggerated clonidine-induced reduction of NA turnover is a poor determinant of exaggerated reduction of concomitant cortisol secretion.

In summary, adaptive or pathological alterations of pre-and/or postsynaptic adrenoceptor sensitivity in response to noradrenergic overactivity may led to uncoupling or "loss of signal-to-noise ratio" (Siever et al. 1992) of the normally well-synchronized interaction between the NA system and the HPA axis. Conceivably the uncoupling process may be most critical during times of stress, a period typically associated with clinical worsening in patients with PD; under these circumstances, activation of the noradrenergic system is accompanied by suboptimal modulation of the HPA axis. Of note in this context is the high stability across challenges of baseline and $\Delta_{\max }$ cortisol in both healthy volunteers as well as patients with PD, suggesting preservation of certain aspects of the homeostatic mechanisms regulating HPA axis activity despite the uncoupling process. Given the complex nature of central neuroendocrine function, other neurobiological systems are likely to contribute to the pathophysiology of the uncoupling process observed in this sample of PD patients and almost certainly in the mediation of fluoxetine's antipanic effects. 
A shortcoming of the study is the absence of clonidine challenge data in PD patients who have been treated for a longer period than three months. It is conceivable that with continued clinical improvement often observed with ongoing specific serotonin reuptake inhibitors (SSRI) treatment (Schneier et al. 1990), coupling between the NA system and the HPA axis may become more evident. This latter possibility appears unlikely, as the plasma cortisol to plasma MHPG relationships during the PD patients' second clonidine challenge exhibited an increase of nonsignificant correlations in the reverse of those observed in the controls' second challenge. This latter observation supports the view that despite clinical improvement, coupling between the NA system and HPA axis was evident only at nonsignificant levels in the opposite direction to that observed in the healthy controls. Loss of a significantly exaggerated percentage of MHPG decrease to the second clonidine challenge supports a degree of normalization of NA function in fluoxetine-treated PD patients. Prospective clonidine studies of PD subjects who receive SSRI treatment for a longer period of time are clearly indicated.

The view of adrenergic overdrive in acute PD is supported in the current study by the increased baseline plasma MHPG levels observed in the untreated PD patients versus the controls, a finding that has been shown in some but not all previous studies (see Abelson et al. 1992 for review). When we compare NA measures from the first challenge with cortisol measures from the second challenge, NA/HPA coupling is strikingly evident in the healthy volunteers. As controls undergo a similar "visit" effect to that observed in the patients -an equivalent decline in baseline MHPG levels - it is feasible that elevated MHPG levels in response to the novelty of the test situation in the controls, but not in PD patients is closely related to HPA axis function in a nonnovel situation - the second clonidine challenge.

In summary, abnormal responsivity to clonidine as reflected by the percentage of MHPG and cortisol decreases during clonidine challenge persists despite clinical improvement. Moreover, uncoupling of NA and HPA function appears to be a feature of PD patients who are in an acute and fluoxetine-treated state.

\section{ACKNOWLEDGMENTS}

This research was supported in part by an NIMH Research Scientist Award to J.M.G., an NIMH Research Scientist Development Award to L.P., and a Clinical Training Grant and NIMH Research Scientist Development Award to J.D.C.

\section{REFERENCES}

Abelson JL, Glitz D, Cameron OG, Lee MA, Bronzo M, Curtis GC (1992): Endocrine, cardiovascular and behavioral responses to clonidine in patients with panic disorder. Biol Psychiatry 32:18-25

American Psychiatric Association (1987): Diagnostic and Statistical Manual of Mental Disorders, 3rd ed., rev. Washington, DC, American Psychiatric Association

Brambilla F, Bellodi L, Arancio C, Nobile P, Perna G (1994): $\alpha_{2}$-Adrenergic receptor sensitivity in panic disorder, II: Cortisol response to clonidine stimulation in panic disorder. Psychoneuroendocrinology 20(1):11-19

Butler PD, Weiss JM, Stout JC, Nemeroff CB (1990): Corticotropin-releasing factor produces fear-enhancing and behavioral activating effects following infusion into the locus ceruleus. J Neurosci 10(1):176-183

Cameron OG, Smith CB, Lee MA, Hollingsworth PJ, Hill EM, Curtis GC (1990): Adrenergic status in anxiety disorders: Platelet alpha-2-adrenergic receptor binding, blood pressure, pulse and plasma catecholamines in panic and generalized anxiety disorder patients and in normal subjects. Biol Psychiatry 28:3-20

Charney DS, Heninger GR, Breier A (1984): Noradrenergic function in panic anxiety: Effects of yohimbine in healthy subjects and patients with agoraphobia and panic disorder. Arch Gen Psychiatry 41:751-763

Charney DS, Heninger GR (1986): Abnormal regulation of noradrenergic function in panic disorders: Effects of clonidine in healthy subjects and patients with agoraphobia and panic disorder. Arch Gen Psychiatry 43:1042-1055

Charney DS, Deutch AY, Krystal JH, Southwick SM, Davis M (1993): Psychobiologic mechanisms of posttraumatic stress disorder. Arch Gen Psychiatry 50(4):294-305

Chrousos GP, Gold PW (1992): The concepts of stress and stress system disorders. J Am Med Assoc 267(9):12441252

Coplan JD, Papp LS, Martinez J, Pine D, Rosenblum LA, Cooper T, Liebowitz MR, Gorman JM (in press): Persistence of decreased human growth hormone $(\mathrm{HGH})$ response to clonidine in fluoxetine-treated panic disorder patients. Am J Psychiatry

Endicott J, Spitzer RL (1978): A diagnostic interview: The schedule for affective disorders and schizophrenia. Arch Gen Psychiatry 35:837-844

Jimerson DC, Markey SP, Oliver JA, Kopin IJ (1981): Simultaneous measurement of plasma 4-hydroxy-3-methoxyphenylethylene glycol and 3, 4-dihydroxyphenylethylene glycol by gas chromatography mass spectrometry. Biomed Mass Spectrom 8:256-258

Klein DF (1993): False suffocation alarms, spontaneous panics, and related conditions: An integrative hypothesis. Arch Gen Psychiatry 50(4):306-318

Murphy BEP (1967): Some studies of the protein binding of steroids and their application to the micro and ultramicro measurement of various binding radio assay. J Clin Neuroendocrinology Metab 27:973

Nutt DJ (1989): Altered central alpha-2 sensitivity in panic disorder. Arch Gen Psychiatry 46:165-159 
Schneier FR, Liebowitz MR, Davies SO, Fairbanks J, Hollander E, Campeas R, Klein DF (1990): Fluoxetine in panic disorder. J Clin Psychopharmacol 10(2): 119-21

Shrout PE, Fleiss JL (1979): Intraclass correlations: Uses in assessing rater reliability. Psychol Bull 86:420-428

Siever LJ, Trestman RL, Coccaro EF, Bernstein D, Gabriel SM, Owen K, Moran M, Lawrence T, Rosenthal J, Harvath TB (1992): The growth hormone response to clonidine in acute and remitted depressed male patients. Neuropsychopharmocology 6(3):165-177

Spitzer RL, Williams, JBW, Gibbon M, First MB (1990): SCID:
User's Guide for the Structured Clinical Interview for DSM-III-R. Washington DC, American Psychiatric Press

Stein BM, Uhde TW (1988): Cortisol response to clonidine in panic disorder: Comparison with depressed patients and normal controls. Biol Psychiatry 24:322-330

Uhde TW, Tancer ME, Rubinow DR, Roscow DB, Boulenger JP, Vittone B, Gurguis G, Geraci M, Black B, Post RM (1992): Evidence for hypothalamo-growth hormone dysfunction in panic disorder: Profile of growth hormone responses to clonidine, yohimbine, caffeine, glucose, GRF and TRH in panic disorder patients versus healthy volunteers. Neuropsychopharmacology 6(2):101-118 